\title{
Importance of coastal nutrient supply for global ocean biogeochemistry
}

\author{
Xavier Giraud, ${ }^{1,2}$ Corinne Le Quéré, ${ }^{1,3,4}$ and Leticia C. da Cunha ${ }^{1,5}$ \\ Received 15 March 2006; revised 11 October 2007; accepted 11 February 2008; published 17 June 2008.
}

[1] The coastal ocean provides nutrients to the open ocean in accounts that are poorly quantified. We use an ocean biogeochemistry model to assess the importance of the coastal nutrient supply to global ocean biogeochemistry. The model includes full cycles of $\mathrm{P}, \mathrm{Si}$, and $\mathrm{Fe}$, as well as the representation of two phytoplankton groups, two zooplankton groups, and two organic detritus pools. When coastal mixing is enhanced to reproduce the action of tides and storms, primary production and chlorophyll-a (Chla) concentrations show a large increase at the coast and a smaller increase in the open ocean. When coastal nutrient supply is enhanced to reproduce sediment resuspension or river supply, both the coastal ocean and the open ocean primary production and Chla concentration increase in comparable amounts. In agreement with the definition of nutrient limitation areas in the model, coastal export of P-excess impacts mainly the subtropical oligotrophic areas, Si-excess impacts the Arctic Ocean and some coastal areas, and Fe-excess impacts the east equatorial Pacific, North Atlantic and North Pacific, and the Southern Ocean. Modeled Chla is closest to observations when the input ratio of $\mathrm{Fe}$ to $\mathrm{P}$ and $\mathrm{Si}$ is enhanced.

Citation: Giraud, X., C. Le Quéré, and L. C. da Cunha (2008), Importance of coastal nutrient supply for global ocean biogeochemistry, Global Biogeochem. Cycles, 22, GB2025, doi:10.1029/2006GB002717.

\section{Introduction}

[2] The coastal ocean covers $\sim 10 \%$ of the total area of the world ocean. Yet in these regions $15 \%$ of the oceanic primary production, half of the carbonate burial and most of the burial of organic carbon take place [Gattuso et al., 1998; Liu et al., 2000; Muller-Karger et al., 2005]. Thus the coastal ocean should take a major place in global biogeochemical modeling. Unfortunately, state-of-the-art global Ocean Biogeochemistry Models (OBMs) have so far neglected the specific processes that take place in the coastal ocean. Although there has been intensive research in the coastal regions (e.g., Land-Ocean Interaction in the Coastal Zone, LOICZ [Crossland, 2005]), global biogeochemical flux and budget estimates for these regions are still poorly constrained.

[3] The uncertainties on the nutrient budget in the coastal domain are due to the complexity of the processes happening there. The role of the coastal zone as a buffer between continents and open ocean is unclear and is thought to be extremely region-dependent. The coastal ocean is subject to

\footnotetext{
${ }^{1}$ Max Planck Institute for Biogeochemistry, Jena, Germany.

${ }^{2}$ Now at MARUM - Center for Marine Environmental Sciences and Faculty of Geosciences, University of Bremen, Bremen, Germany.

${ }^{3}$ Now at School of Environmental Sciences, University of East Anglia, Norwich, UK.

${ }^{4}$ Also at British Antarctic Survey, Cambridge, UK.

${ }^{5}$ Now at Leibnitz-Institut für Meereswissenschaften, Marine Biogeochemie, Kiel, Germany.

Copyright 2008 by the American Geophysical Union. 0886-6236/08/2006GB002717
}

the influence of human activities, which add to the variability and uncertainty of the nutrient budget of the coastal zone [Ver et al., 1999; Rabouille et al., 2001]. In addition to riverine supply and exchanges with the open ocean, the source and sink of nutrients for the coastal domain are various. Continental shelf sediments are thought to be potentially nonnegligible sources of nutrients for the water column [Johnson et al., 1999]. This may be displayed by permanent benthic diffusive fluxes [McManus et al., 1997; Zabel et al., 1998] or during sediment resuspension events of various origins [Fanning et al., 1982; Spagnoli and Bergamini, 1997; Tengberg et al., 2003]. The atmospheric deposition and submarine groundwater discharge are also potentially important sources of nutrients to the coastal ocean [Paerl, 1997; Slomp and Van Cappellen, 2004]. The respiration associated with the sediment surface photosynthesis may lead to non negligible carbon and nutrients recycling [Jahnke et al., 2000]. In the case of the South Atlantic Bight, this may account for approximately half of the total metabolic carbon turnover in this shelf system [Jahnke et al., 2005].

[4] OBMs poorly represent the coastal zone and the continental shelves. Both the coarse resolution and the topography smoothing tend to alter the representation of the continental shelf. The smoothing process of the topography, required for numerical stability reasons, suppresses the sharpness of the continental shelf break, even for higher resolution models. The coarse resolution reduces the number of grid cells having a shallow bottom depth. Without these two important morphological aspects, a sharp shelf 
break and an extended continental shelf, oceanic circulation may be badly simulated in this domain. In the case of coastal upwelling in the presence of an extended continental shelf, a recirculation cell is described to take place between the coast and the continental shelf break [SCOR, 1975]. The associated nutrient recirculation, which should enhance the biological production, may therefore be absent in a coarse resolution model. Most OBMs do not explicitly consider mixing processes due to tides. Nevertheless, tidal currents are part of the driving forces for the distribution of suspended particulate matter (SPM) concentrations [Prandle et al., 2000] or enhanced mixing [Xing et al., 1999], and hence biology [Prandle, 1997]. Considering the sediment resuspension or the organic matter transformation on the seafloor would require an early diagenesis module, which is usually not included in OBMs.

[5] Despite the weaknesses of OBMs to downscale processes in this specific coastal domain, OBMs remain the most appropriate tools to study the impact on global biogeochemical processes. This study does not aim to establish a strict budget of nutrients in the coastal zone, but to assess, within the uncertainties in the nutrient budgets, what are the impacts of processes in the coastal ocean for global biogeochemistry.

[6] Section 2 describes the model used for this study. Section 3 presents the sensitivity tests performed to evaluate the impact of individual and combined additional/perturbed nutrient sources to the coastal ocean. Results are presented in section 4 and discussed in section 5 .

\section{Model Description and Baseline Simulation}

[7] We use the OPA general circulation model [Madec et al., 1998] coupled to the PISCES biogeochemistry model [Aumont et al., 2003]. The grid of OPA is irregular and has an averaged resolution of $2^{\circ}$ in longitude and $1^{\circ}$ in latitude. The vertical distribution includes 31 levels, with $10 \mathrm{~m}$ resolution in the top $100 \mathrm{~m}$. In most coastal regions, the horizontal resolution is too coarse to represent accurately the shelf break features and the topography of the continental margin. The vertical eddy viscosity and diffusivity coefficients are computed from a 1.5 turbulent closure model based on a prognostic equation for the turbulent kinetic energy, and a closure assumption for the turbulent length scales [Gaspar et al., 1990; Blanke and Delecluse, 1993; Madec et al., 1998]. The boundary conditions on velocity are no-slip.

[8] The PISCES biogeochemistry model is derived from the HAMOCC5 model [Aumont et al., 2003]. A complete description is given by Aumont et al. [2003]. We describe hereafter only important aspects necessary to interpret the results presented here. PISCES includes two phytoplankton types (diatoms and nanophytoplankton). Growth rates are calculated based on the limitation of three nutrient pools $(\mathrm{P}$ or total $\mathrm{N}-, \mathrm{Si}$, and $\mathrm{Fe}$ ). This aspect is of great interest when studying the effects of changing nutrient ratios in the coastal ocean itself, and the effects on the different nutrient-limited areas of the open ocean. For the nutrient limitation, individual growth rates based on Michaelis-Menten formulations are calculated for each nutrient. The final growth rate, for diatoms or nanophytoplankton, is the minimum of these individual growth rates (see Aumont et al. [2003, Table 2] for the equations). Total nitrogen nutrient (nitrate + ammonium) and phosphate are linked by Redfield ratio and thus are indifferently represented by the model variable "phosphate" $(\mathrm{P})$. The C:P ratio is constant in planktonic variables. The Fe cycle is represented by a simple parameterization which considers the scavenging of Fe below the mixed layer and loosely restores Fe to a value of $0.6 \mathrm{nM}$, as by Aumont et al. [2003]. Fe and Si are deposited from the atmospheric dust fields of Tegen and Fung [1995]. We consider a solubility of $2 \%$ and $7.5 \%$ for $\mathrm{Fe}$ and $\mathrm{Si}$, respectively. A change compared to the biogeochemical model of Aumont et al. [2003], is a parameterization to consider sources and sinks due to nitrogen fixation and denitrification. The description of the parameterization of these processes can be found in the additional material of Aumont and Bopp [2006]. PISCES also includes two zooplankton types (micro- and mesozooplankton), DOC, and two detrital pools sinking at 3 and $50 \mathrm{~m} \mathrm{~d}^{-1}$, respectively. We considered a constant river input of $\mathrm{P}$ and $\mathrm{Si}$, of 17 and $5 \mathrm{Gmol} \mathrm{a}^{-1}$ respectively, and distributed this impact at the location of the river mouths [Ludwig et al., 1996; Ludwig and Probst, 1998]. We considered no Fe input, assuming a complete precipitation in estuaries. da Cunha et al. [2007], in a study of the potential impact of changes in river nutrient supply on global ocean biogeochemistry, tested the effect of removing between $80 \%$ and $99 \%$ of Fe from the dissolved phase in estuaries [Chester, 1990; Dai and Martin, 1995]. Their model includes the same parameterization of Fe limitation as ours. da Cunha et al. [2007] showed that including further sources of $\mathrm{Fe}$ from rivers compared to the actual contribution does not increase much coastal ocean primary production. In their simulations, the excess Fe in the coastal ocean is exported to the open ocean, enhancing Chla concentrations/primary production, especially in eastern margin areas. The export of nutrient excess from the coastal domain is therefore the key point. This is also the main focus of this study, and the nutrient supplies that we introduce are meant to stimulate this export (see also discussion in section 4.2.4 about the distribution of the nutrient sources in coarse model boxes).

[9] Initial conditions for all tracers are based on observations, as described by Le Quéré et al. [2000]. The model was forced by daily winds and precipitation fields from the National Center for Environmental Prediction/National Center for Atmospheric Research (NCEP/NCAR) reanalysis [Kalnay et al., 1996], from 1991 to 2000. This is the second and last difference from the model of Aumont et al. [2003]: we used reanalyzed daily forcing fields whereas they used offline monthly mean fields. Heat fluxes and the latent heat of evaporation are computed based on the temperature difference between the sea surface and the bottom of the atmosphere (from NCEP). The partial pressure of atmospheric $\mathrm{CO}_{2}$ increases following the observed values corresponding to the years of simulation [Keeling and Whorf, 2005].

[10] The biogenic silica and phosphorus budgets are closed through a compensation of inputs (dust, rivers and additional coastal sources in the following experiments) by removing particulate and dissolved organic nutrients from 
the bottom layer. The removal proportion is the same in each bottom cell and is scaled to balance the global inputs. The additional coastal supplies are considered in this budget-balance, and do not introduce a trend in the total amount of nutrients.

[11] The evaluation of an OBM should go through a full set of proxies including the export production of organic matter and calcium carbonate from the euphotic layer, the alkalinity distribution, or the gas exchanges at the oceanatmosphere interface. This study is focused on shallow areas where such proxies may be less relevant. In the following sections, we will use therefore the surface chlorophyll-a (Chla) concentration as the major proxy to compare data and model outputs, and model outputs among themselves. Satellite data of surface Chla concentration have the advantage of being global. The coastal ocean is highly productive, and in these areas the surface Chla concentrations are high. However, colored dissolved organic matter and detrital suspended particles make difficult the calibration of algorithms for the interpretation of satellite images for surface Chla concentrations in the case II waters [Hooker and McClain, 2000; Pinkerton et al., 2003]. Under these conditions, we will consider that SeaWiFS data provide an upper limit for surface Chla concentrations in the coastal band. We also comment on the results considering the variations of species composition.

[12] Figure 1 presents the comparison of annual mean surface Chla concentration between the SeaWiFS data and the baseline simulation (average based on the last 5 years of a 10 years simulation, see also end of section 3 ). It shows some agreement between model results and observations concerning the global distribution of oligotrophic gyres and high latitude Chla maximums. However, it appears that the modeled Chla concentration is overestimated in the southern ocean as well as in the sub-tropical gyres. On the other hand, the model under-estimates the surface Chla concentrations in the equatorial and coastal upwelling systems, in the North Atlantic and in general in the entire coastal ocean. Therefore one intention of this study is also to see how the improvement of the simulation of the coastal nutrient sources may influence and improve the global oceanic structures of the open ocean.

[13] Figure 2 presents the annual nutrient limitation of diatoms and nanophytoplankton growth for the baseline simulation. The nanophytoplankton is mostly Fe-limited in high latitudes, equatorial Pacific and South Atlantic, and P-limited in subtropical North Atlantic, Indian Ocean, and north and south subtropical Pacific. The diatom nutrient limitation presents a similar pattern as nanophytoplankton for $\mathrm{Fe}$ and $\mathrm{P}$. In addition, diatoms are mainly Si-limited in northern high latitudes, and other regions like in eastern North Pacific, south of Australia, south of Arabian Peninsula, off Northwest Africa and Southeast South America. Because of the model resolution, it is not possible to distinguish fine regional patterns along the coasts.

\section{Sensitivity Analysis}

[14] In order to represent the impact of missing tidal mixing, smoothing of topography and coarse resolution in
OBM, we performed a first sensitivity test with increased vertical mixing coefficient in the coastal grid points of the OBM, defined as the first ocean grid points along the various coasts. The vertical mixing rate is multiplied by 100 in the coastal ocean to maximum annual mixing of $\sim 10^{4} \mathrm{~m}^{2} / \mathrm{s}$. It is applied to biogeochemical passive tracers only during the 10 years of simulation.

[15] The additional mixing in the coastal grid points modifies the vertical profile of nutrient concentrations, mostly leading to higher concentrations in the surface ocean. The comparison of these vertical profiles, at each time step, between the mixing experiment and the baseline simulation, provides the location where the nutrient concentrations have increased. This difference is calculated after the ecosystem has reacted and is therefore lower range estimation. At any time and any coastal grid point, the positive difference between the mixing and baseline simulation is recorded to be used as additional nutrient supply in the next sensitivity cases. In three separate experiments, we add the individual nutrients sources ( $\mathrm{P}, \mathrm{Si}$ or $\mathrm{Fe}$ ) one at the time in the coastal ocean. The individual nutrient supplies are added at each time step during the 10 years of simulation, with the same vertical and horizontal distribution as the mixing experiment. The averaged values of the nutrient supply are presented in Table 1 . The purpose of adding individual nutrients entrained in the mixing experiment, without actually mixing, is to be able to change one nutrient at a time, and to learn about the model behavior related to each nutrient. Adding once again the mixing, would modify the distribution of all nutrients. Calculating the sources from a mixing experiment is based on the idea that it provides a nutrient load distribution that is linked the local conditions. Table 2 presents potential nutrient sources from the continental shelf sediments. As a first approach, we can consider that the availability of nutrients in these shelf sediments is the result of the biological activity in the above water column. The following simulations include different combinations of nutrient supplies, and we finish with the combination of nutrient supplies and the mixing.

[16] We tested therefore the combination of nutrient supplies to the coastal domain (Table 1). The first combination corresponds to the addition of $\mathrm{P}, \mathrm{Si}$, and $\mathrm{Fe}$ together in quantities and spatial distributions identical to the previous simulations. The nutrient ratio induced by the mixing experiment is respected, but this experiment differs from the mixing experiment because the source of nutrients is provided additionally. This experiment is referred hereafter as simulation "IP" (for Initial Proportions). In the next two combinations, we modified this nutrient ratio, so that we can compare the importance of the nutrient ratio versus total nutrient supply. These experiments are referred hereafter as simulations "NP" (for Non Proportional) and we modified the nutrient ratio as explained in the following paragraph.

[17] Table 2 presents a summary of the river input to the coastal ocean, the amount of nutrient supplied to the surface by the mixing experiment, and a short list of potential nutrient sources from the continental shelf sediments. The river input estimations are issued from a compilation done by da Cunha et al. [2007], based on global river runoff data from Ludwig et al. [1996] and Döll and Lehner [2002], and 

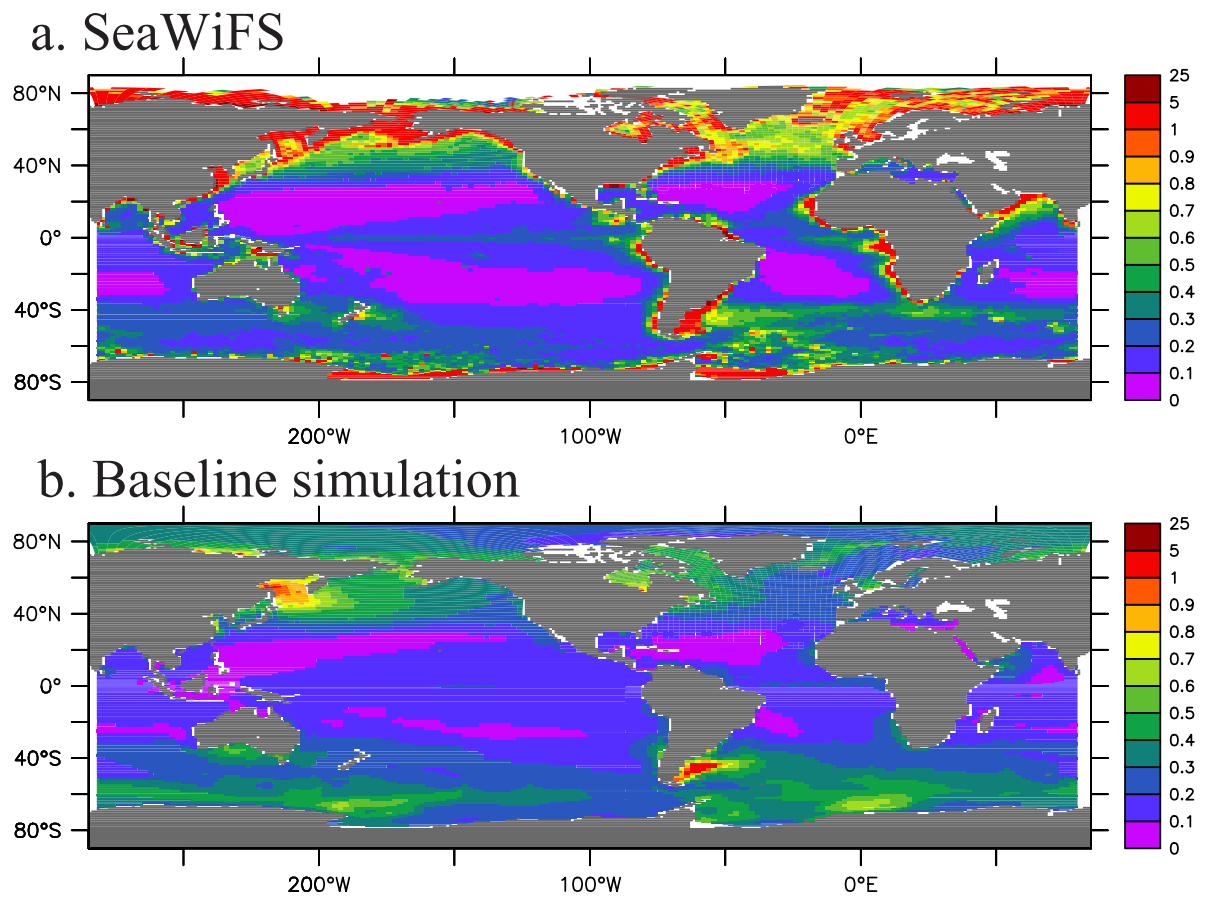

\section{c. Deviation: Model/Data - 1}
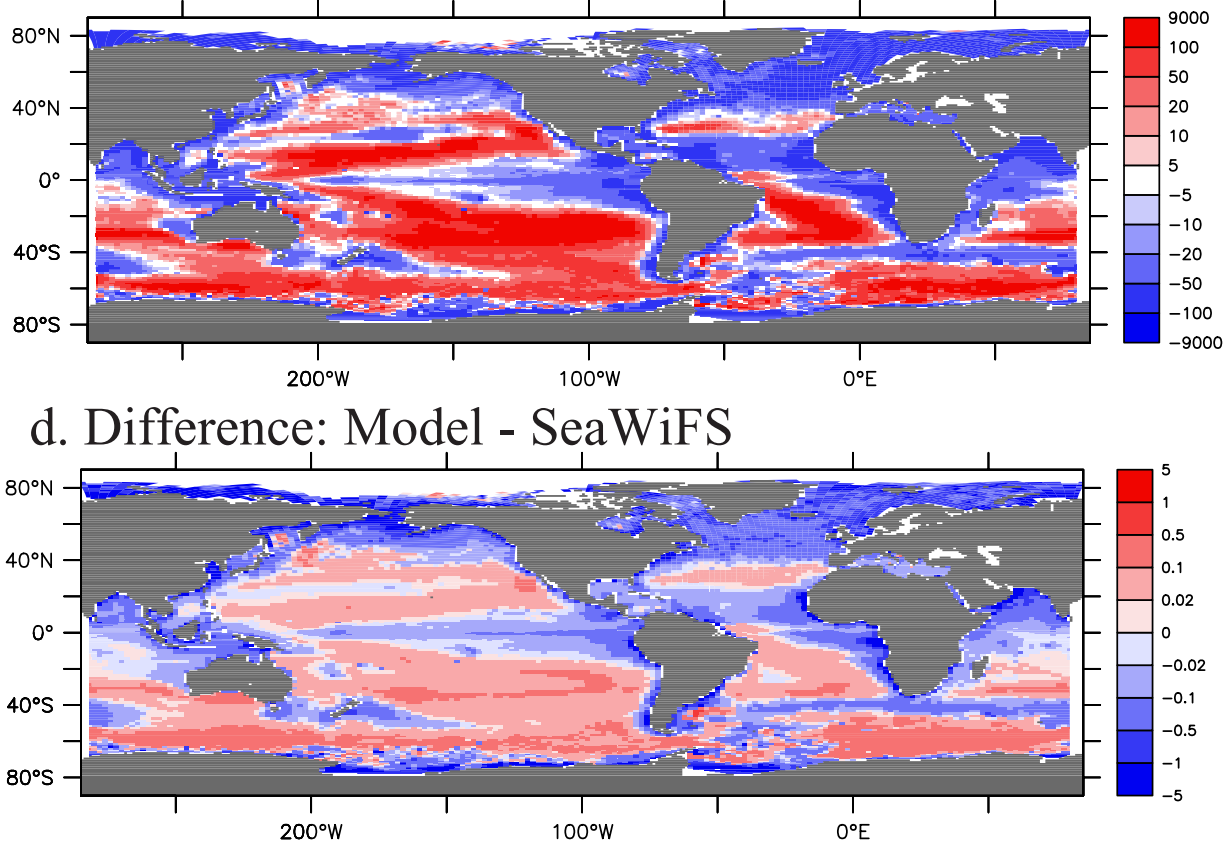

Figure 1. Annual mean surface Chla concentration from (a) SeaWiFS data and (b) the baseline simulation (in $\mathrm{mg} \mathrm{Chla} \mathrm{m}^{-3}$ ). (c) Deviation between model results and data (difference divided by data,

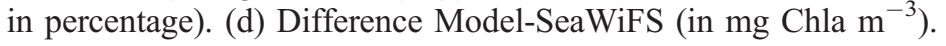

the estimates of Smith et al. [2003] for phosphate, Treguer et al. [1995] for silicate, and Chester [1990] for dissolved iron. The second part of this table is a short review of sediment resuspension experiments or measurements of diffusive benthic fluxes in coastal environments. Each single experiment or estimation reports the nutrient fluxes at one location, with particular sediment characteristics. The values presented in Table 2 report the nutrient load due to the resuspension event itself (Gulf of Mexico), permanent benthic fluxes (eastern South Atlantic, Californian continental margin), or benthic fluxes before and after a resuspension event (Sweden shelf, northern Adriatic Sea shelf). To evaluate the impact of resuspension on a global scale, we have extrapolated these values to the whole coastal ocean (3.6 $10^{13} \mathrm{~m}^{2}$ ), assuming homogenous sediment conditions over the whole coastal domain and a continuous and 


\section{a. Diatoms}

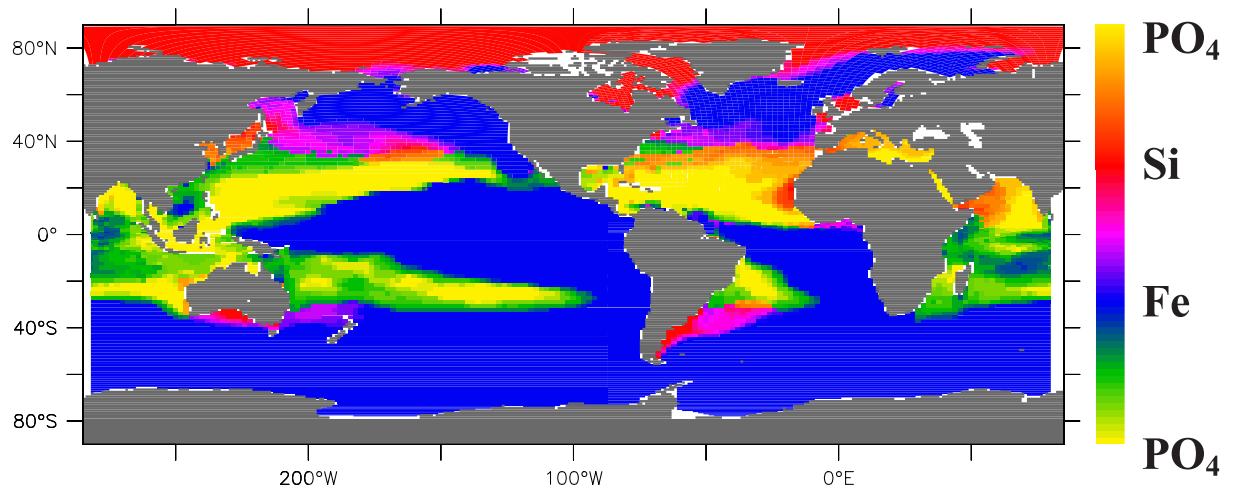

\section{b. Nanophytoplankton}

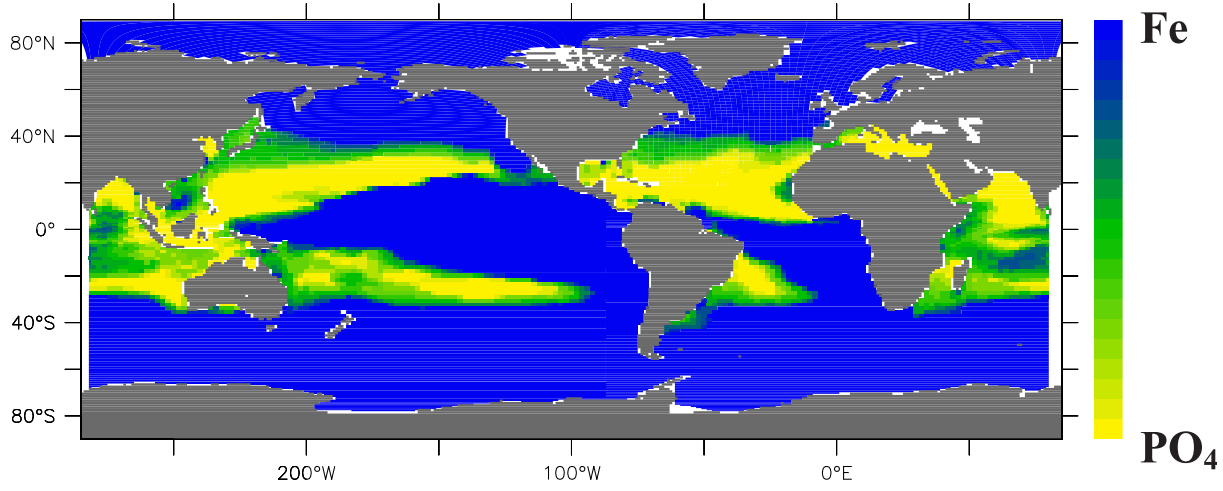

Figure 2. Nutrient limitation of phytoplankton growth for the baseline simulation (a) for diatoms and (b) for nanophytoplankton. Red: limitation dominated over the year by Si (only for diatoms); Yellow: limitation dominated by P; Blue: limitation dominated by Fe.

constant process in time for diffusive benthic fluxes. According to these values of potential nutrient sources and river inputs, it appears that the mixing and IP experiments give low values of $\mathrm{Fe}$ and $\mathrm{Si}$, and high values of $\mathrm{P}$ compared to the coastal input including all possible processes. In order to reproduce the proportions presented by the benthos sources, we performed a simulation, named "NP_Alt", in which we add P with the same spatial distribution as the IP simulation but reduced by a factor 10, and the Si and Fe multiplied by a factor 20 and $2.10^{3}$, respectively. This leads to total fluxes close to the minimum values observed in Table 2 (see also Table 1). The second simulation, named "NP Low", considers the same sources as simulation "NP Alt", but with all fluxes further reduced by a factor 10 . The difference between simulations NP Alt and NP_Low is therefore on the quantity of the nutrient supply, but not their relative ratio, which is the same in both simulations. The simulation NP_Low is motivated by considerations on the location of the nutrient supply: when nutrients are added to the coastal grid points, they are uniformly distributed within the model grid box, rather than higher concentration along the coast and lower offshore. In effect, the model mixes entirely the nutrients within this grid box. Considering that a tenth of the fluxes is available in the water column in the simulation NP_Low minimizes this artificial mixing and considers that $90 \%$ of the nutrients are deposited in the coastal ocean.

[18] Finally, we performed two last simulations to explore further the discussion about the relative importance of the different nutrients and processes. The simulation "Fe 200" considers the same Fe source as simulation NP Low, but has no $\mathrm{Si}$ or $\mathrm{P}$ inputs. This will provide information about the importance of $\mathrm{Fe}$ compared to the other nutrients in the previous simulation results. The last simulation "NP Low Mix" combines the nutrient supply of simulation NP Low and the increased mixing rate of simulation "Mixing". This is motivated by the fact that the mobiliza-

Table 1. Simulation Names and Associated Nutrient Supply in the Coastal Ocean (Annual Average)

\begin{tabular}{lccc}
\hline $\begin{array}{c}\text { Simulation } \\
\text { Name }\end{array}$ & $\begin{array}{c}\text { P Supply } \\
\text { Gmol a }^{-1}\end{array}$ & $\begin{array}{c}\text { Si Supply } \\
\text { Tmol a }\end{array}$ & $\begin{array}{c}\text { Fe Supply } \\
\mathrm{Gmol} \mathrm{a}^{-1}\end{array}$ \\
\hline Mixing & 620 & 0.088 & $1.610^{-3}$ \\
$\mathrm{P}$ & 620 & 0 & 0 \\
$\mathrm{Si}$ & 0 & 0.088 & 0 \\
$\mathrm{Fe}$ & 0 & 0 & $1.610^{-3}$ \\
$\mathrm{IP}$ & 620 & 0.088 & $1.610^{-3}$ \\
$\mathrm{NP}$ _alt & 62 & 1.76 & 3.2 \\
$\mathrm{NP}$ _low & 6.2 & 0.17 & 0.32 \\
Fe_200 & 0.0 & 0.0 & 0.32 \\
NP_low_mix & 6.2 & 0.17 & 0.32 \\
\hline
\end{tabular}


Table 2. Nutrient Supplies to the Coastal Ocean

\begin{tabular}{lccc}
\hline & Coastal P-Supply Gmol a & Coastal Fe-Supply Gmol a $^{-1}$ \\
\hline River input data & $35.2^{\mathrm{a}}-64^{\mathrm{b}}$ & Coastal Si-Supply Tmol a $^{-1}$ & $1.6-6.4^{\mathrm{d}}$ \\
Mixing simulation & 620 & $0.4^{\mathrm{c}}$ & 1.688 \\
Gulf of Mexico $^{\mathrm{e}}$ & $57-160^{\mathrm{j}}$ & 1.6 & 23 \\
$\begin{array}{l}\text { Sediment resuspension } \\
\text { Sweden shelf }\end{array}$ & $507^{\mathrm{j}}$ & 31 \\
$\begin{array}{l}\text { After resuspension event } \\
\text { Northern adriatic sea shelf }\end{array}$ & $507^{\mathrm{j}}-2480$ & 40 \\
$\begin{array}{l}\text { Before resuspension event } \\
\text { Northern adriatic sea shelf } \\
\text { After resuspension event }\end{array}$ & $640-924^{\mathrm{j}}$ & $5.6-13.2$ & $392^{\mathrm{k}}$ \\
$\begin{array}{l}\text { Eastern South Atlantic } \\
\text { Diffusive benthic fluxes }\end{array}$ & $150-510$ & & $<0$ \\
Californian cont. margin & & & $3.8-48$ \\
Diffusive benthic fluxes & $520-1310$ & & \\
\hline
\end{tabular}

First line: from the river runoff. Second line: from the mixing simulation. The bottom part presents a set of sediment resuspension experiments or benthic diffusive flux measurements from the literature. Examples 4 and 5 are benthic diffusive fluxes. They are therefore permanent. We assume they are applied constantly over the year. Examples 2 and 3 are fluxes occurring before and after one resuspension event. We provide this raw information without proposing a proportion of occurrence of these two extreme situations (before or after a resuspension) along the year. The annual mean flux at this particular location is certainly in-between. Example 1 refers to the nutrient supply due to the resuspension of a certain quantity of sediments, based on the concentration of nutrients in the sediments. It can be expressed as flux only if we assume the quantity of sediments resuspended over a time period. We propose a minimal assumption of 10 storm events per year, leading to a total resuspension of $10 \mathrm{~mm}$ of sediment. All values have been extrapolated to the whole coastal ocean assuming homogeneous characteristics over the shelves, with a total surface of $3.610^{13} \mathrm{~m}^{2}$.

${ }^{\mathrm{a}}$ Harrison et al. [2005].

${ }^{\mathrm{b}}$ Smith et al. [2003].

${ }^{\mathrm{c}}$ Treguer et al. [1995].

${ }^{\mathrm{d}}$ Upper and lower limits assuming a precipitation of $80 \%$ or $95 \%$ in the estuaries areas [Chester, 1990].

${ }^{\mathrm{e}}$ From Fanning et al. [1982], assuming an average of 10 storm events per year, with an effect of $1 \mathrm{~mm}$ of sediment resuspension per event.

${ }^{\mathrm{f}}$ From Tengberg et al. [2003].

${ }^{\mathrm{g}}$ From Spagnoli and Bergamini [1997].

${ }^{\mathrm{h}}$ From Zabel et al. [1998].

${ }^{\mathrm{i}}$ From McManus et al. [1997].

${ }^{\mathrm{j}}$ The present value corresponds to a $\mathrm{N}$ flux measurement, expressed in P assuming a N/P ratio of 18 [Smith et al., 2003].

${ }^{\mathrm{k}}$ Total $\mathrm{Fe}$ (other values are dissolved $\mathrm{Fe}$ ).

tion of the nutrient supplies mentioned above may be linked to physical processes other than mixing.

[19] Each simulation has been performed over a period of ten years. The first five years allows for fast equilibrium of the surface ocean structures to the new conditions of the coastal ocean. The last five years are used to present an average picture of the new situation. Figure 3 shows the evolution of the difference between each simulation and the baseline run for the global mean surface Chla concentration and the sea-to-air $\mathrm{CO}_{2}$ flux. It shows that the biogeochemical system becomes stable after a short equilibrium phase of 3-4 years. Using oceanic regions as described by Longhurst [1998], we verified for all simulations that local variations and adjustments also equilibrate at the regional scale. Only a few regions like the North Atlantic and subtropical North Pacific open oceans show a continuous trend after the first 5 years for simulation NP_Low by example. Some long term feedback may exist but are outside the scope of this study. The following results and figures are therefore based on the averaged results of the last 5 years of simulation and are presented as the annual mean over this period.

\section{Results}

\subsection{Increased Mixing}

[20] The higher coastal mixing simulation (Figure 4a) increases the annual mean of surface Chla concentration in all coastal areas, with sparse exceptions in Arctic Ocean and Patagonian coasts, where it can locally decrease. The maximum relative increases, with more than $+100 \%$ Chla concentration, occur in the Gulf of Mexico, in Arabian Sea, and in Indonesian straits. Chla concentrations are also increased in the open ocean of all basins, but show no changes in the east equatorial Pacific and in open ocean south of $35^{\circ} \mathrm{S}$. The variations of diatom concentrations are similar to the Chla trend, with maximum percentage increase relative to the reference simulation all along the coasts. The nanophytoplankton concentration varies similarly to Chla variations in the band $45^{\circ} \mathrm{N}-35^{\circ} \mathrm{S}$. At higher latitudes, the nanophytoplankton concentration decreases (less than $20 \%$ of difference) along the coastal band. The deep chlorophyll maximum is shallower only in the coastal regions having high increase of surface Chla concentrations.

[21] Between 50 and $80 \%$ of the increase in Chla concentration can be attributed to the chlorophyll to carbon (Chla:C) ratio for diatoms and nanophytoplankton, which slightly increases in all places where the phytoplankton concentrations increase. Chlorophyll for both phytoplankton groups is parameterized using the photoadaptative model of Geider et al. [1998]. The Chl:C ratio will therefore depends on available light energy during the primary production.

[22] The increase in Chla concentration in the open ocean is accompanied by an increase of both meso- and microzooplankton. A decrease of the zooplankton concentration occurs only along some coastal areas. We attribute this 

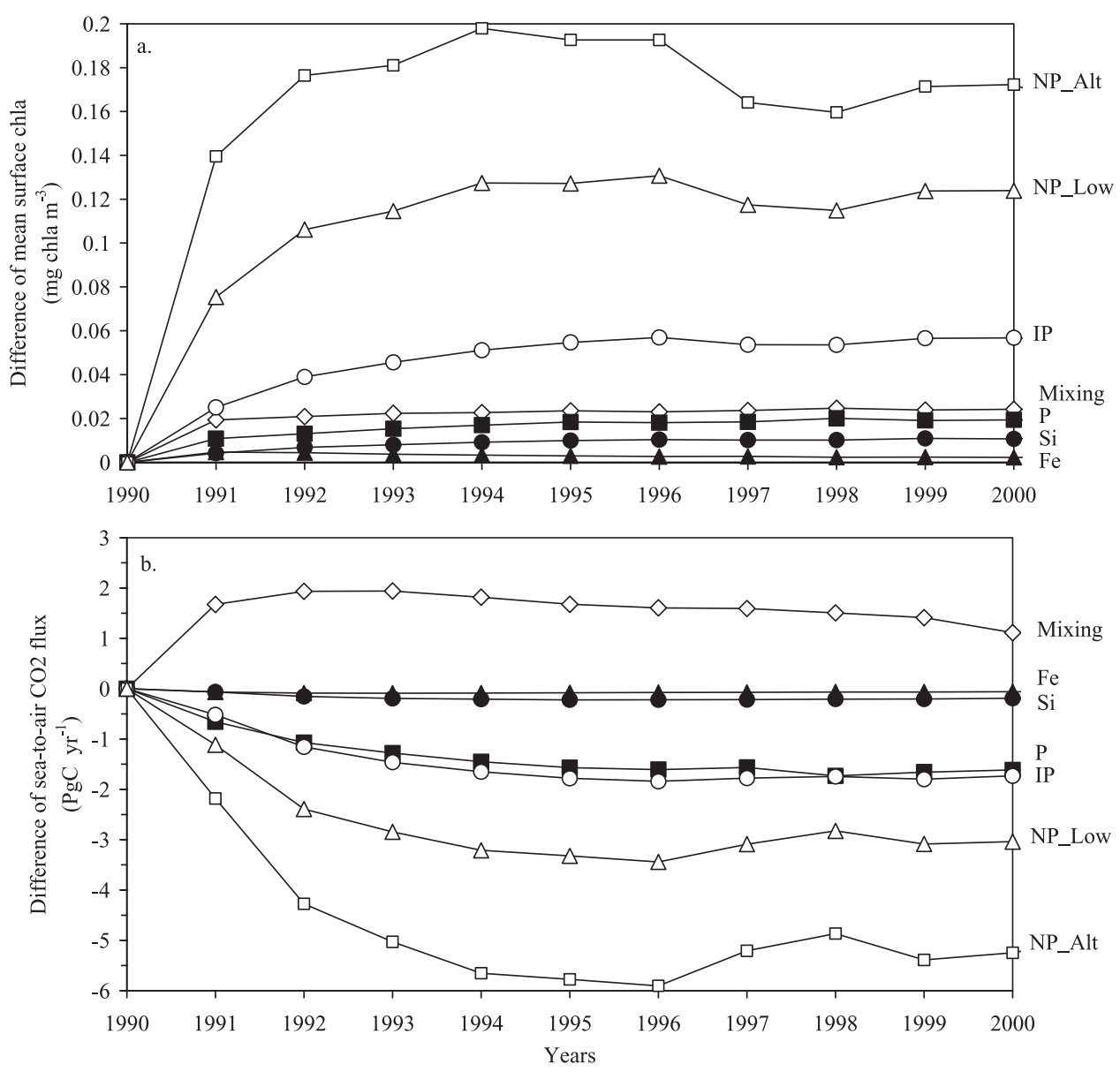

Figure 3. Time evolution of the difference of (a) global mean Chla concentration and (b) sea-to-air $\mathrm{CO}_{2}$ flux, between each simulation and the baseline simulation. A negative sea-to-air $\mathrm{CO}_{2}$ flux difference indicates that the oceanic sink for the atmospheric $\mathrm{CO}_{2}$ is increased. Simulation names: Mixing (white diamonds), P (black squares), Si (black circles), Fe (black triangles), IP (white circles), NP (white triangles).

decrease to an effect of the vertical mixing, which seems to be unfavorable to the zooplankton.

[23] We computed the export of nutrients and phytoplankton from the coastal band of the model to the open ocean, in the top $50 \mathrm{~m}$ of the ocean, between $60^{\circ} \mathrm{S}$ and $70^{\circ} \mathrm{N}$. The model results show an increase of $\mathrm{P}, \mathrm{Si}$, and phytoplankton export of $64 \%, 340 \%$ and $37 \%$, respectively, and a decrease of the Fe export of $12 \%$. The increase in diatom concentration along the entire coastal domain is therefore the consequence of the additional nutrient supply to the surface due to the mixing, and has led to an over consumption of iron. P- and Si-excess are exported from the coastal band to the open ocean. It explains the distribution of Chla variations in the open ocean: changes in diatom or nanophytoplankton occurred in Si- or P-limited areas of the reference run, and not in Fe-limited areas (Figure 2).

\subsection{Individual Nutrient Sources}

\subsubsection{Additional $P$}

[24] The excess of $P$ does not act primarily on the coastal ocean as in the previous sensitivity test of increased mixing (Figure 4b). The coasts of eastern Pacific, Southeast Atlan- tic and Antarctic show no changes in either Chla concentration or group composition. This is in agreement with the fact that these places are Fe-limited for both phytoplanktonic groups (Figure 2), and are thus not affected by the supply of P. The Chla concentration increases in the Indian Ocean, North Atlantic, Southeast Atlantic and North and Southwest Pacific. The minimum value of surface Chla concentration on the global ocean increases to $0.045 \mathrm{mg}$ Chla $\mathrm{m}^{-3}$ and the oligotrophic central gyres are therefore less pronounced. The areas of Chla concentration increase correspond to former P-limited areas for both groups (Figure 2). The nanophytoplankton shows only increased concentrations in parallel to the Chla increase, whereas the diatoms may decrease in many regions, often in relation with Si-limited areas. Both meso- and microzooplankton show the same trend as the Chla concentration. The deep chlorophyll maximum becomes shallower only in areas of increasing surface Chla concentration.

[25] The Arctic Ocean, which is Fe-limited for both groups, shows a decrease in Chla concentration, but no systematic shift in phytoplankton composition. The Bering Strait region, which has the highest decrease in Chla, shows 
a. Simulation Mixing

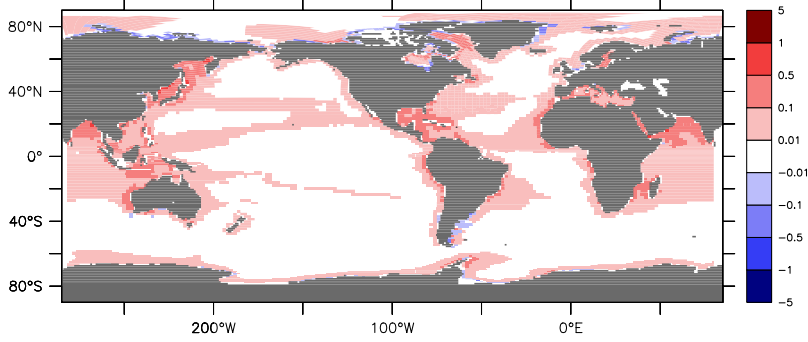

b. Simulation $\mathrm{P}$

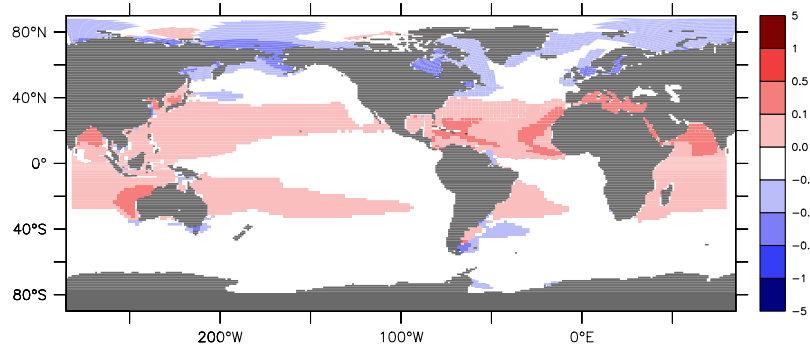

c. Simulation $\mathrm{Si}$

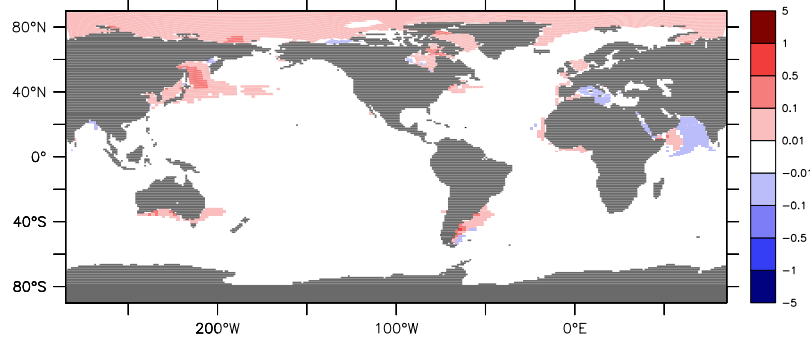

d. Simulation $\mathrm{Fe}$

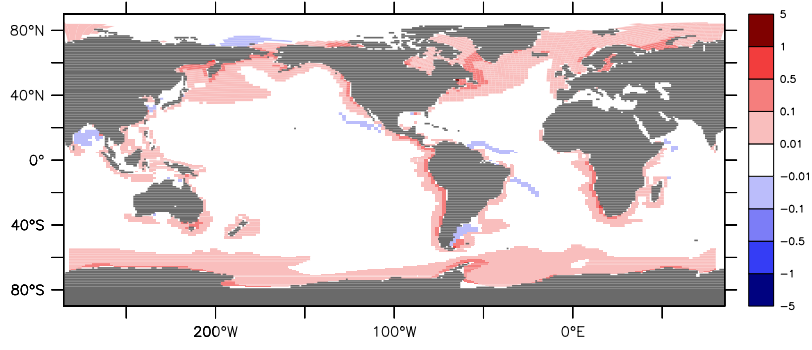

e. Simulation IP

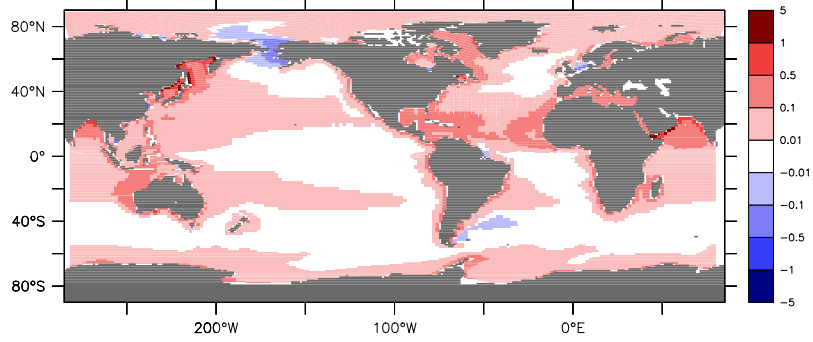

f. Simulation NP_Alt

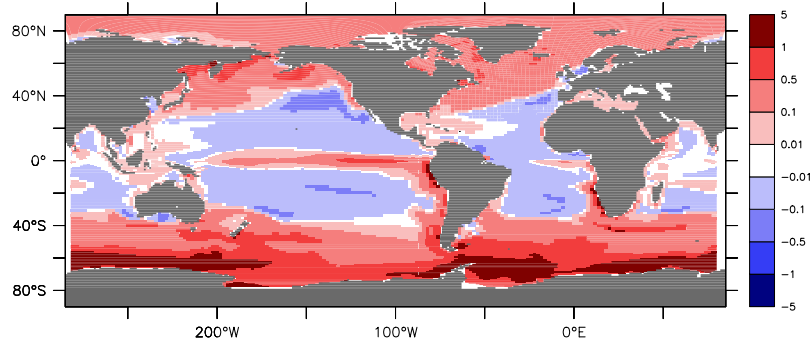

g. Simulation NP_Low

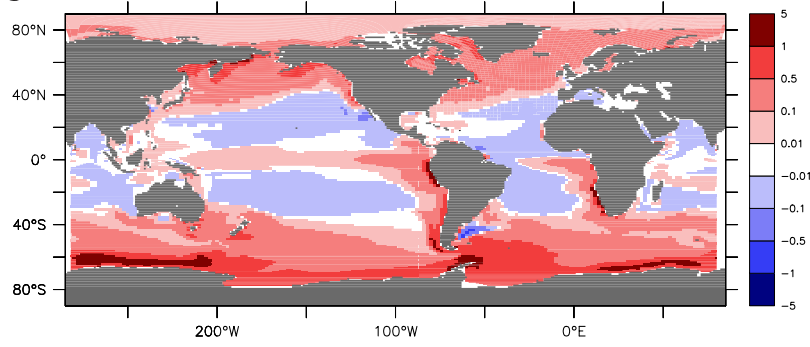

h. Simulation Fe_200

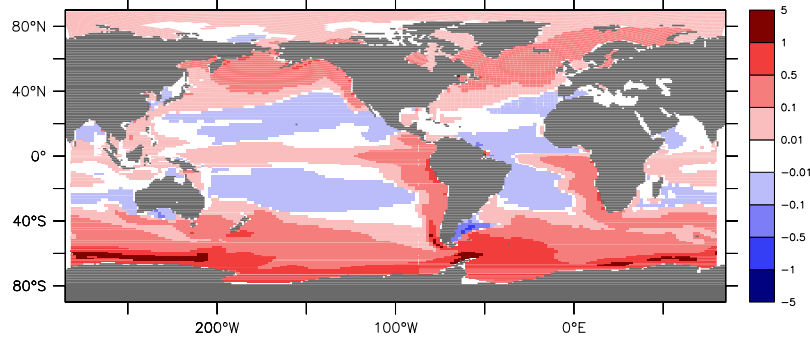

i. Simulation NP_Low_Mix

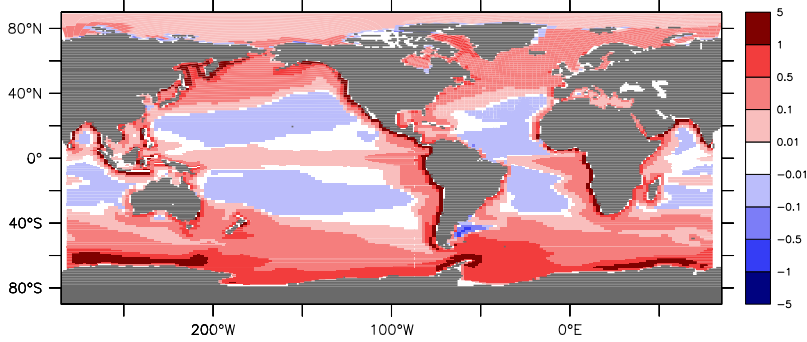

Figure 4. Difference of annual mean surface Chla concentration (in $\mathrm{mg} \mathrm{Chla}^{-3}$ ) between the different simulations and the baseline simulation. Comparison for an increased mixing (a), or with additional sources of P (b), Si (c) or Fe (d), simulations IP (e), NP_Alt (f), NP_Low (g), Fe_200 (h), and NP_Low_Mix (i).

an important diatom decrease (more than 50\%) whereas nanophytoplankton increases. In the other parts of the Arctic Ocean, the nanophytoplankton does not show significant changes and diatoms alternatively increase and decrease. A remarkable feature of this whole region is a decrease of the surface iron concentration, which is a paradox, since iron 
was already the limiting nutrient. In parallel $\mathrm{P}$ and $\mathrm{Si}$ concentrations are higher since they are not consumed by Fe-limited phytoplankton groups. The origin of the iron depletion does not come from the Artic Ocean itself but may be located externally. Considering that the Bering Strait throughflow constitutes a major pathway for nutrient transport to the Arctic Ocean [Cooper et al., 1997, and references herein], we attribute the particular pattern of the Bering Strait, further influencing the rest of the high latitudes, to a local impoverishment in Fe, that is observed in the model, due to an excess of consumption in the North Pacific Ocean.

[26] In the Southeast Atlantic, the P-supply favors the diatom and nanophytoplankton growth close to the coast, and leads therefore to a higher consumption of $\mathrm{Si}$ and $\mathrm{Fe}$ locally. These two nutrients are therefore more depleted further offshore, which leads to lower concentrations of diatoms in the subtropical Southeast Atlantic.

\subsubsection{Additional Si}

[27] The excess of Si increases the Chla concentration in all areas formerly Si-limited for diatoms (Figure 4c). The increase in diatom concentration is partly compensated by a decrease in the nanophytoplankton concentrations in the same areas, due to the competition for other nutrients ( $\mathrm{P}$ and $\mathrm{Fe})$. It explains the global moderate increase in Chla concentration.

[28] The mesozooplankton shows exactly the same variations as the Chla or diatom concentration. The microzooplankton and nanophytoplankton show a decrease in concentration at the same locations (mostly in the Arabian Sea, Mediterranean Sea, Japanese Sea, central North Pacific, subtropical North Atlantic, and south of Western Australia). This behavior of the zooplankton groups is in agreement with their feeding sources. The meso- and microzooplankton are preferentially grazing on the diatoms and nanophytoplankton, respectively.

[29] The Arabian Sea shows a particular case of a decrease

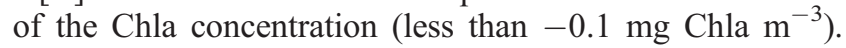
This pattern is due to a local seesaw effect, between the eastern and western parts of this area. South of the Arabian Peninsula, the diatoms are Si-limited (Figure 2a). The introduction of a Si-supply favors the diatom growth in this area, and therefore a higher export production (with a maximum difference of $+28 \mathrm{gC} \mathrm{m}^{-2} \mathrm{a}^{-1}$ ), which implies a higher consumption of all nutrients. This higher consumption of nutrients in the western part induced a deficit in the eastern part of the northern Indian Ocean, and therefore lower concentrations of both planktonic groups. A similar seesaw seems to exist off Northwest Africa.

\subsubsection{Additional $\mathrm{Fe}$}

[30] The excess of $\mathrm{Fe}$ increases the Chla concentrations along most of the coasts, in the East and North Pacific, and in the East and North Atlantic (Figure 4d). In contrast to the previous experiments, the Fe supply has also an impact on the southern ocean, where Chla concentrations increase along the coast. No modification of the open ocean Chla concentration is noticeable apart from a slight decrease of Chla in restricted areas of the open ocean. The zooplankton shows exactly the same trend, and the deep chlorophyll maximum is shallower along the coasts at places having the highest Chla increase (Southeast Pacific, eastern equatorial Atlantic, and Indonesian straits). Because many coastal zones are Fe-limited in the baseline simulation (Figure 2), the Fe supply is used locally and leads to a higher consumption of $\mathrm{P}$ and $\mathrm{Si}$. The quantification of the nutrient transport from the coastal band of the model to the open ocean shows an increase of Fe export of $75 \%$ and a decrease of $\mathrm{P}$ export of $10 \%$. The coastal band of the model, between $60^{\circ} \mathrm{S}$ and $70^{\circ} \mathrm{N}$, was exporting silica to the open ocean in the baseline simulation, and is now a sink in this $\mathrm{Fe}$ simulation. The export of $\mathrm{Fe}$ is accompanied with an increased export of phytoplankton of $19 \%$. The excess Fe export is therefore rapidly consumed in the proximal open ocean and does not affect the large open ocean.

\subsubsection{Sensitivity Test of Combined Sources}

[31] In this section we compare the effect of the five different combinations of nutrient supplies to the coastal domain, IP, NP_Alt, NP_Low, Fe_200, and NP_Low_Mix. The experiments NP differ from simulation IP by the ratio of nutrient sources. The simulations NP_Alt and NP_Low differ from each other by the amount of nutrient supply, but they have identical nutrient ratios.

[32] In simulation IP (Figure 4e), all coastal regions have higher Chla concentrations, with the exception of the Bering Strait region, where it decreases. In each coastal region, the simulation IP provides a supply of all three nutrients, including the local limiting nutrient. This particular supply contributes to locally higher production. The other nonlimiting elements were already in excess and their supply simply further contributes to this excess.

[33] In the open ocean, Chla increases mostly in former Plimited areas. Thus the pattern of the Chla changes between $40^{\circ} \mathrm{N}$ and $35^{\circ} \mathrm{S}$ is comparable to the one already described for the simulation P. In the southern ocean, the extent of changes is similar to the one produced by the simulation Fe. The increase observed in the Okhotsk Sea and extending in the North Pacific, can be related to the one produced by the simulation Si. Finally, the decrease simulated around the Bering Strait and offshore the Atlantic Patagonian coast already appeared in the simulation P.

[34] The variations of diatom concentrations match the Chla variations, showing the same increase along the coasts and in the open ocean areas previously depicted, and a decrease in the Bering Strait region and offshore of the Atlantic Patagonian coast (Figures 5a and 5b). The nanophytoplankton significantly increases only in regions formerly P-limited. Once again, exceptions can be found in the Bering Strait region and in the Arctic Ocean, where the nanophytoplankton shows an increase and a slight decrease (less than 10\%), respectively. These high northern latitudes are not P-limited for the two phytoplanktonic groups. For the same reasons as given for simulation $\mathrm{P}$, we attribute the particular pattern of the Bering Strait to a local impoverishment in Fe due to an excess of consumption in the North Pacific Ocean. Similarly, the Southeast Atlantic decrease in Chla is due to a seesaw of nutrients consumption and availability between the coastal area and the offshore region. The deep chlorophyll maximum is shallower where surface Chla is increasing, and thus between $40^{\circ} \mathrm{S}$ and $40^{\circ} \mathrm{N}$.

[35] The second combination experiment, NP_Alt, considers a nutrient supply function where $\mathrm{P}$ is reduced in 


\section{a. Baseline simulation}

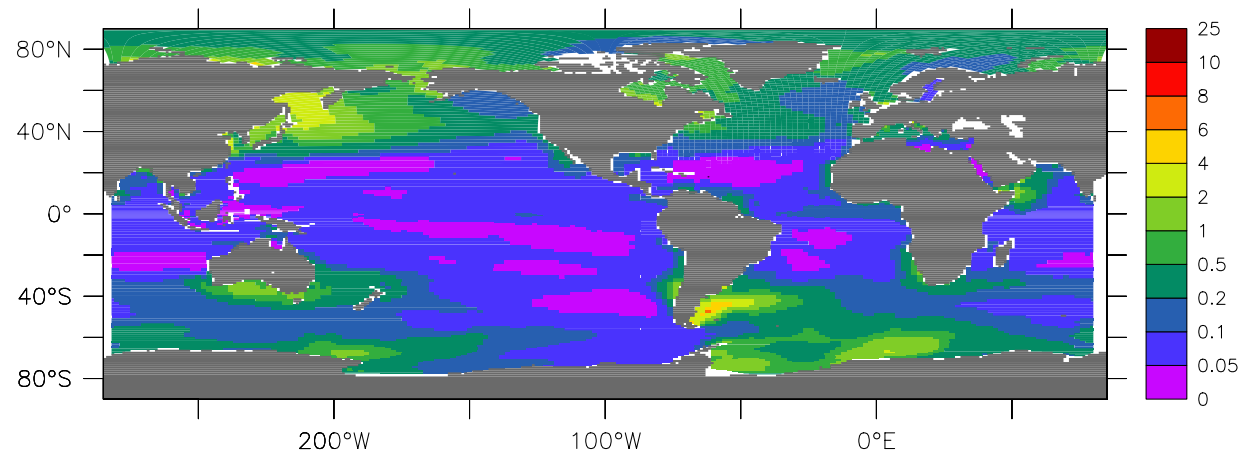

\section{b. Simulation IP}

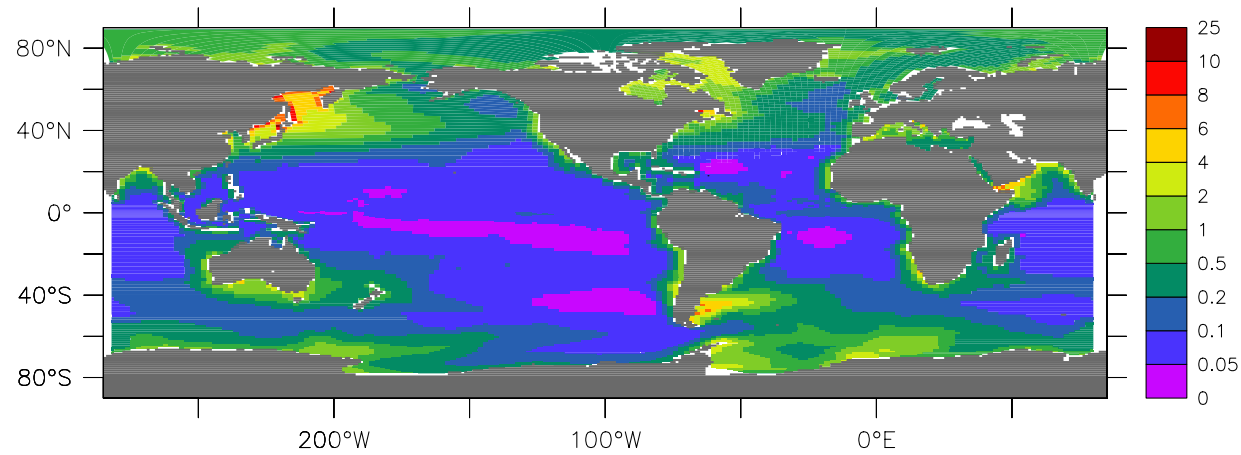

\section{c. Simulation NP_Low}

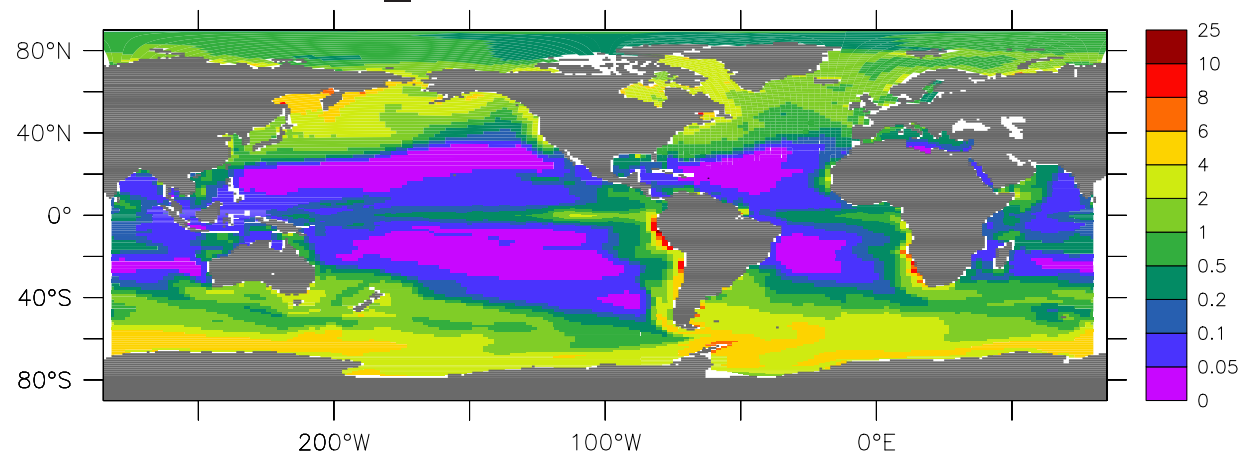

Figure 5. Annual mean of surface diatom distribution $\left(\mathrm{mmol} \mathrm{m}^{-3}\right)$.

comparison to $\mathrm{Si}$ and Fe sources, so that the total supply fluxes match the minimum values of benthos fluxes presented in Table 2. Here again, a nutrient supply in the coastal ocean has important impacts on global patterns (Figure 4f). Whether in the coastal or open ocean, the Chla variations cannot be clearly and simply related to the previous nutrient limitation maps. Many coastal regions show higher Chla concentrations, but many exceptions occur, like south of Australia, on the Pacific coasts between California and Colombia, the Brazilian coasts, the Western European shelves and the North and Central African coasts. All open ocean areas show surface Chla variations compared to the reference simulation. The oligotrophic central gyres, between $40^{\circ} \mathrm{S}$ and $40^{\circ} \mathrm{N}$, show a decrease of Chla concentration. High latitudes and the east equatorial Pacific, from the South America coast until $180^{\circ} \mathrm{E}$, show important an increase of Chla concentration.
[36] The phytoplanktonic groups reacted differently to the nutrient input. The diatoms increased almost everywhere (with more than a doubling in concentration in high latitudes) apart from central oligotrophic regions where they decrease. The general trend of nanophytoplankton is a decrease in their concentration, with a maximum decrease of $60 \%$ in the eastern North Pacific, except areas like the equatorial Pacific, the coasts of the "warm pool", the coasts of Southwest Africa, the southern ocean, the eastern subtropical Atlantic, and the western coast of India, where it increases by around $+40 \%$.

[37] The simulation NP Low shows similar results as the previous simulation NP_Alt in the structure and intensity of Chla variations (Figure $\overline{4} \mathrm{~g}$ ). The main differences lie in the equatorial Pacific, where the increased Chla concentration extend to the warm pool, in the east equatorial Atlantic, showing a clearer increase of Chla, and in the high latitudes, 
Table 3. Root Mean Square of Difference (RMSD) of Surface Chla Concentration Between the Simulations and SeaWiFS Data (in $\left.\mathrm{mg} \mathrm{Chla} \mathrm{m}^{-3}\right)^{\mathrm{a}}$

\begin{tabular}{lccc}
\hline & \multicolumn{3}{c}{ RMSD $\left(60^{\circ} \mathrm{S}-60^{\circ} \mathrm{N}\right)$} \\
\cline { 2 - 4 } Simulation & Global Ocean & Open Ocean & Coastal Ocean \\
\hline Baseline & 0.62 & 0.13 & 1.29 \\
Mixing & 0.60 & 0.13 & 1.26 \\
$\mathrm{P}$ & 0.62 & 0.14 & 1.30 \\
$\mathrm{Si}$ & 0.62 & 0.13 & 1.29 \\
$\mathrm{Fe}$ & 0.61 & 0.13 & 1.27 \\
$\mathrm{IP}$ & 0.60 & 0.13 & 1.25 \\
NP_Alt & 0.59 & 0.13 & $\mathbf{1 . 2 3}$ \\
NP_Low & $\mathbf{0 . 5 8}$ & 0.12 & $\mathbf{1 . 2 3}$ \\
Fe_200 & 0.59 & $\mathbf{0 . 1 1}$ & 1.24 \\
NP_Low_Mix & 0.59 & 0.12 & 1.24 \\
\hline
\end{tabular}

${ }^{\text {a }}$ See text of section 4.3 for definitions. The lower the RMSD, the closest to SeaWiFS data. In each column, minimum values are in bold, and values lower than the baseline are grey shaded.

where the Chla increase is less pronounced. The coast of northern Indian Ocean shows a Chla decrease instead of the increase observed in simulation NP Alt. The decrease of Chla concentration previously observed in simulation NP Alt in the oligotrophic central gyres is also less pronounced. The diatom distribution (Figure 5c) is also similar to that of simulation NP_Alt, except for the Arctic and Antarctic oceans that show a smaller increase. The nanophytoplankton show also higher concentrations than in the previous simulation in many places like in equatorial Pacific, equatorial Atlantic, south of Africa, and in Arctic Ocean.

[38] The results of the simulation Fe 200 (Figure 4h) are similar to simulation NP_Low (Figure 4g). Minor differences can be found in the intensity of Chla variations along the coasts, but the global patterns are identical. Among the differences, in the Arabian Sea, the source of Fe provided south of Ethiopia, leads to an increase of Chla (both due to increased concentrations of diatoms and nanophytoplankton), and as a consequence further north, a depletion in nutrients and a decrease in Chla concentration. The simulation NP_Low Mix shows also similar results on the global pattern (Figure 4i). Nevertheless, the increased mixing in the coastal domain leads to much higher Chla concentrations almost everywhere and in particular in the warm pool, in the North Pacific and in the Indian Ocean. This is associated to a much higher export production. The open ocean variations are identical to previous simulations NP Low or Fe 200.

[39] In all previous simulations, the meso- and microzooplankton concentrations change according to the variations of the diatoms and nano-phytoplankton, respectively. This is in agreement with their trophic chain relation, and confirms that the zooplankton pool simply reacts to the phytoplankton concentration changes. In no situation, the variations of the zooplankton could counterbalance the increase or the decrease of the phytoplankton.

\subsection{Evaluation of Global Impact}

[40] Table 3 shows the Root Mean Square of Difference (RMSD) of surface Chla concentration between the simulations and SeaWiFS data, for the global ocean as well as the open and coastal ocean components. For this calcula- tion, the distinction between open and coastal ocean is based on the ecological provinces of Longhurst [1998]. Since still very few of the data used to develop the SeaWiFS Chla bio-optical algorithm are from high latitudes [e.g., Richardson et al., 2003; Eiras Garcia et al., 2005], the Table 3 shows the RMSD computed in the band $60^{\circ} \mathrm{S}-$ $60^{\circ} \mathrm{N}$.

[41] The simulation NP Low is closest to observations. It shows better RMSD values for the global ocean, but also for the open and coastal ocean compared to the baseline simulation, and the lowest RMSD values of the set of experiments for the global and coastal oceans.

[42] Figure 6 shows the comparison between the Chla concentration of simulation NP_Low and SeaWiFS data. It shows a better location and extent of the oligotrophic subtropical gyres compared to the baseline simulation (see also Figure 1). The maximum Chla concentration is also better represented along most of the continents and in equatorial bands. The major discrepancy stays in the Antarctic Ocean, with an excess of Chla concentration.

\subsection{Consequences on the Carbon Cycle}

[43] The $\mathrm{CO}_{2}$ sink of the baseline simulation is $-0.61 \mathrm{PgC} \mathrm{a}^{-1}$ and varies between 0.84 and $-5.93 \mathrm{PgC} \mathrm{a}^{-1}$ among the different test simulations (Table 4). The effect of the mixing experiment is to increase the oceanic degassing by $1.45 \mathrm{PgC} \mathrm{a}^{-1}$ (Figure $3 \mathrm{~b}$ and 6 ), so that the global flux becomes positive $\left(+0.84 \mathrm{PgC} \mathrm{a}^{-1}\right.$; Table 4$)$. The degassing is increased on a narrow band along the continents only, between $40^{\circ} \mathrm{S}$ and $50^{\circ} \mathrm{N}$, with maximum values in the eastern Pacific, along California, Mexico and Peru, in the northern Indian Ocean, and off Northwest Africa. This result is coherent with the fact that intermediate $\mathrm{CO}_{2}$ rich waters are brought to the surface, where they release $\mathrm{CO}_{2}$ to the atmosphere. The increase in primary production causes also an increase of the export production of $+1.05 \mathrm{PgC} \mathrm{a}^{-1}$ (Figure 7). The increase in export production occurs at places of higher increase of surface Chla concentration shown on Figure 4a.

[44] The simulations $\mathrm{Si}$ and Fe show a small decrease in sea-to-air $\mathrm{CO}_{2}$ flux $\left(\mathrm{FCO}_{2}\right)$, i.e., the ocean sink increases, and a small increase in export production (Figure 7, Table 4). In these two simulations, the variations of export production and $\mathrm{CO}_{2}$ sink are close in absolute value, and the changes in Chla concentration are limited to the coastal ocean. We conclude that the change in export corresponds to a direct pumping of atmospheric $\mathrm{CO}_{2}$, transferred to the coastal sediments.

[45] The other experiments (P, IP, NP_Alt, NP_Low, Fe 200 and NP_Low_Mix) show much larger variations of the export production $(+0.92,+1.94,+6.75,+4.10,+3.08$ and $+7.52 \mathrm{PgC} \mathrm{a}^{-1}$ respectively) and $\mathrm{FCO}_{2}(-1.63,-2.76$, $-5.32,-3.09,-2.42$ and $-2.43 \mathrm{PgC} \mathrm{a}^{-1}$ respectively; Figure 7). Both the increase of the export production and the increase of $\mathrm{CO}_{2}$ sink are due to the external input of nutrients, which modifies the primary production not only in the coastal ocean, but also in the open ocean.

[46] In all simulations, the spatial distribution of changes in $\mathrm{CO}_{2}$ fluxes and export production follows the trend of the surface Chla concentration variations. An increase of Chla 


\section{a. SeaWiFS}

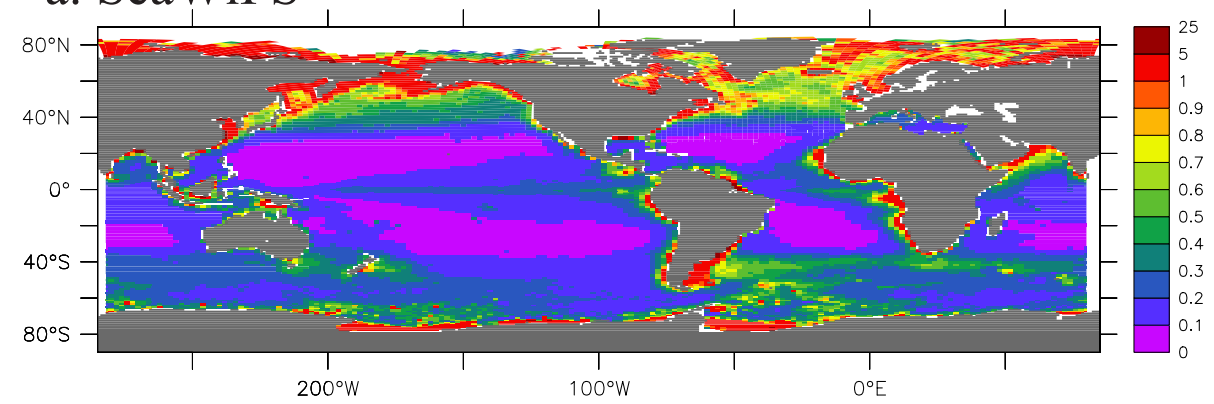

b. Simulation NP_Low

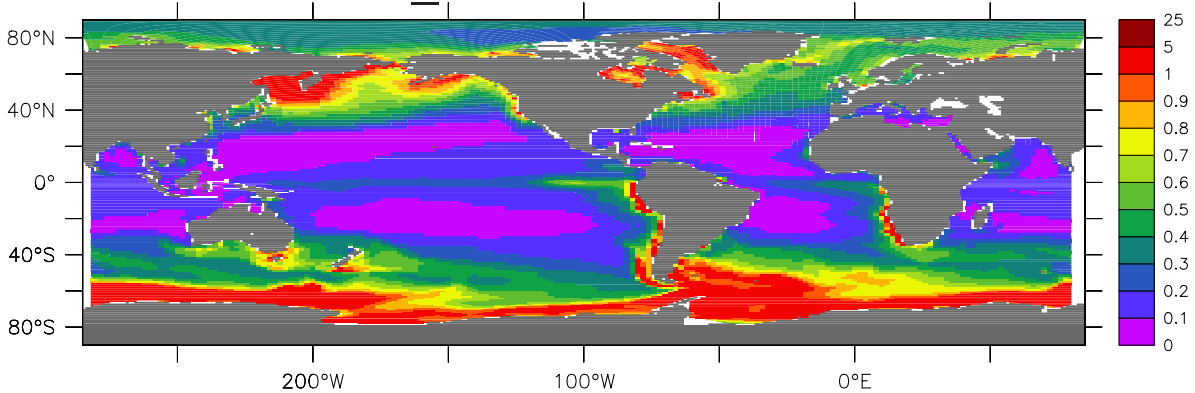

\section{c. Deviation: Model/Data - 1}

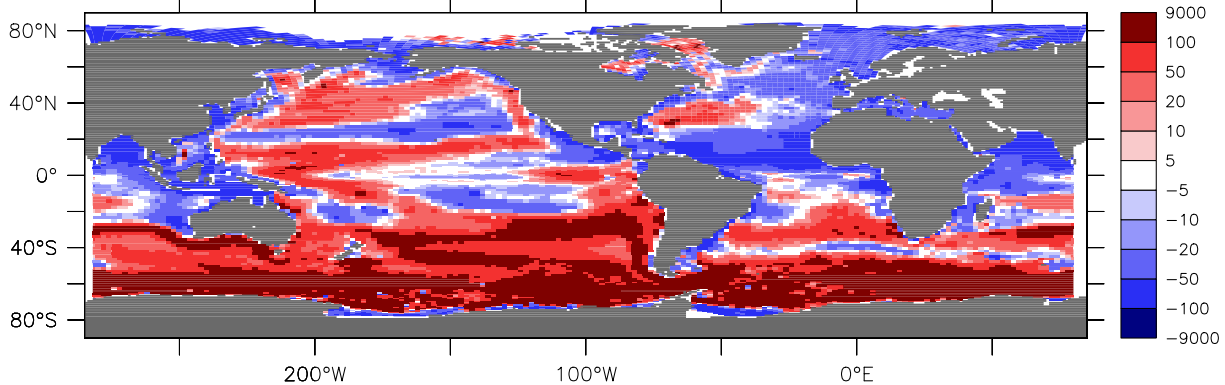

\section{d. Difference: Model - SeaWiFS}

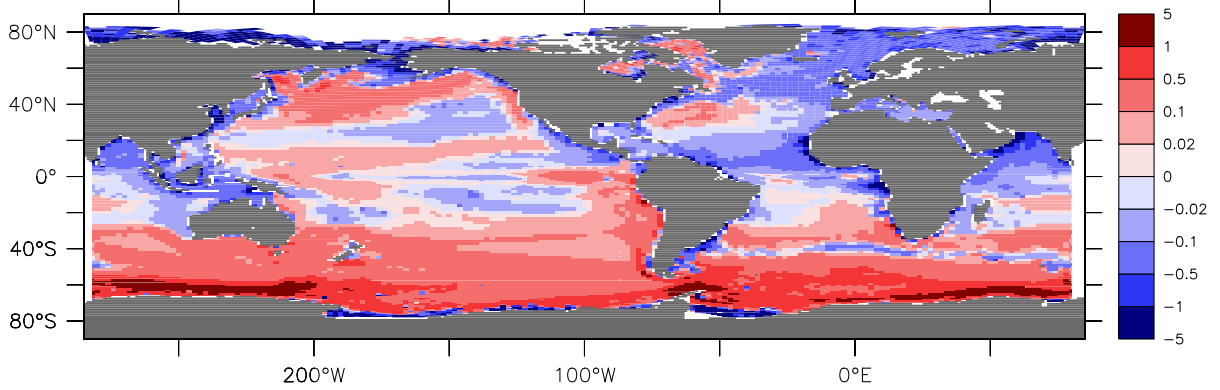

Figure 6. Annual mean surface Chla concentration from (a) SeaWiFS data and (b) the simulation NP Low (in mg Chla $\mathrm{m}^{-3}$ ). (c) Deviation between model results and data (difference divided by data, in percentage). (d) Difference Model-SeaWiFS (in $\mathrm{mg}$ Chla $\mathrm{m}^{-3}$ ).

concentration is usually accompanied with an increase of export production and an increase of atmospheric $\mathrm{CO}_{2}$ pumping. The variations of $\mathrm{CO}_{2}$ fluxes are more widely distributed over great areas, whereas the export production variations are restrained to the locations of maximum Chla variations. No significant variations of $\mathrm{CO}_{2}$ flux or export production is to be seen in the Arctic Ocean, despite some variations of Chla concentration in a few experiments. In the particular case of simulations $\mathrm{NP}$, the $\mathrm{CO}_{2}$ pumping is strongly increased where Chla increases, but is also slightly reduced in subtropical oceans where the Chla concentration decreased. As a result, almost all of the global ocean acts as a sink for atmospheric $\mathrm{CO}_{2}$, and the Pacific and Atlantic equatorial oceans show extremely reduced $\mathrm{CO}_{2}$ degassing compared to the baseline simulation.

[47] The relative importance of the coastal band for seato-air $\mathrm{CO}_{2}$ fluxes and export production is shown in Table 4 . All simulations except the mixing experiment show a 
Table 4. Surface Chla Concentration, Sea-to-Air $\mathrm{CO}_{2}$ Flux $\left(\mathrm{FCO}_{2}\right)$, Export Production (Pexp), and Primary Productivity (PP) for Each Simulation (Global Mean, Averaged Over the Last 5 Years of Experiment)

\begin{tabular}{|c|c|c|c|c|c|c|c|}
\hline Simulation & $\begin{array}{l}\text { Chla-Conc, } \\
\text { mgChla m }{ }^{-3}\end{array}$ & $\begin{array}{l}\mathrm{FCO}_{2,} \\
\mathrm{PgC} \mathrm{a}^{-1} \\
\end{array}$ & $\begin{array}{c}\text { Coastal Fraction } \\
\text { of } \mathrm{FCO}_{2}\end{array}$ & $\begin{array}{c}\text { Pexp, } \\
\mathrm{PgC} \mathrm{a}^{-1}\end{array}$ & $\begin{array}{c}\text { Coastal Fraction } \\
\text { of Pexp }\end{array}$ & $\begin{array}{c}\mathrm{PP} \\
\mathrm{PgC}^{-1} \\
\end{array}$ & $\begin{array}{l}\text { Fraction of PP } \\
\text { from Diatoms } \\
\end{array}$ \\
\hline Baseline & 0.22 & -0.61 & 0.75 & 4.73 & 0.21 & 75.68 & 0.05 \\
\hline Mixing & 0.24 & 0.84 & 0.80 & 5.78 & 0.28 & 85.41 & 0.07 \\
\hline $\mathrm{P}$ & 0.24 & -2.24 & 0.45 & 5.65 & 0.22 & 86.83 & 0.04 \\
\hline $\mathrm{Si}$ & 0.22 & -0.68 & 0.73 & 4.83 & 0.22 & 75.07 & 0.06 \\
\hline $\mathrm{Fe}$ & 0.23 & -0.82 & 0.68 & 5.00 & 0.23 & 77.57 & 0.06 \\
\hline IP & 0.27 & -3.37 & 0.48 & 6.67 & 0.29 & 92.29 & 0.07 \\
\hline NP_alt & 0.39 & -5.93 & 0.28 & 11.48 & 0.24 & 80.74 & 0.30 \\
\hline NP_low & 0.34 & -3.70 & 0.33 & 8.83 & 0.27 & 83.58 & 0.20 \\
\hline $\mathrm{Fe} \_-200$ & 0.33 & -3.03 & 0.30 & 7.81 & 0.22 & 88.58 & 0.12 \\
\hline NP_low_Mix & 0.40 & -3.04 & 0.21 & 12.25 & 0.44 & 100.73 & 0.23 \\
\hline
\end{tabular}

decrease of the coastal fraction of atmospheric $\mathrm{CO}_{2}$ pumping, indicating that the open ocean reacted to the coastal modifications of nutrient sources, becoming a greater sink for atmospheric $\mathrm{CO}_{2}$. This effect is more visible for simulations NP, where this fraction falls around 30\%. The fraction of export production occurring in the coastal band is relatively stable for all simulations, between $21 \%$ and $29 \%$, except for simulation NP Low Mix, where this fraction rises up to $44 \%$ (Table $\overline{4}$ ). The combination of the vertical mixing and additional nutrient supplies is therefore extremely efficient at increasing the export production on a local scale.

\section{Discussion and Conclusions}

[48] Our sensitivity experiments highlight two ways in which the coastal ocean may influence the global ocean biogeochemistry. First, excess nutrients $(\mathrm{P} / \mathrm{N}, \mathrm{Si}$ or $\mathrm{Fe})$ in the coastal ocean can increase biological activity locally if the nutrient is limiting production, which will cause an impoverishment of the other non-limiting nutrients. The impoverished nutrients will then reduce biological activity in the coastal or open regions where they are advected. Such a seesaw effect explains the decrease in Chla concentration in the Arabian Sea in the simulation Si and off the coast of Argentina in simulation P. This seesaw effect is also visible on a global scale for all simulations NP where the oligotrophic regions of the open ocean between $40^{\circ} \mathrm{S}$ and $40^{\circ} \mathrm{N}$ become more oligotrophic, while the coastal regions become more active. Second, when excess nutrients in the coastal ocean are not limiting production locally, they will not be used locally but will be advected and enhance biological activity offshore. This is the case of experiments Mixing, P or IP.

[49] The simulation NP_Low was designed to reduce the nutrient fluxes compared to NP Alt without changing the nutrient ratio. Results from NP $\bar{L}$ Low show identical distribution of the changes as NP Alt, in spite of the fact that nutrient fluxes are one order of magnitude lower. Given the set of parameters and the way the nutrient limitation is defined in this model, we conclude that the quantity of the nutrient released appears to be of secondary importance compared to the nutrient ratio.

[50] Our model simulations suggest that the impact of the coastal ocean on the open ocean biogeochemistry is greatly dependent on which nutrient is advected from the coastal region. The nutrient advected is controlled by the nutrient availability itself and by its consumption in the coastal domain. This was highlighted by the different sensitivity analysis with single nutrient supply and the simulation IP. Thus the ratio of nutrients supplied to the coastal ocean by the various processes is a key control on the impact of the coastal ocean for global ocean biogeochemistry.

[51] The observed nutrient fluxes presented in Table 2 show big variations between estimates, but both sediment resuspension and diffusive benthic fluxes are comparable to or higher than the river fluxes. This short review highlights the importance of sediments as a nutrient source for the coastal ocean. Johnson et al. [1999] considered that the resuspension of particles during upwelling events along the Californian margin may be an essential source of $\mathrm{Fe}$ to sustain the high primary production of this coastal upwelling system. Nevertheless, the estimation of these sedimentary nutrient fluxes is still approximate. The difficulty of this estimation lies in the extrapolation of single values to extended areas, and in the estimation of the duration and frequency of the sediment resuspension due to short events such as storms. The estimation of Fe fluxes is also dependent of the micro-environment. A resuspension event may be accompanied by a release of $\mathrm{Fe}$, but also by the re-

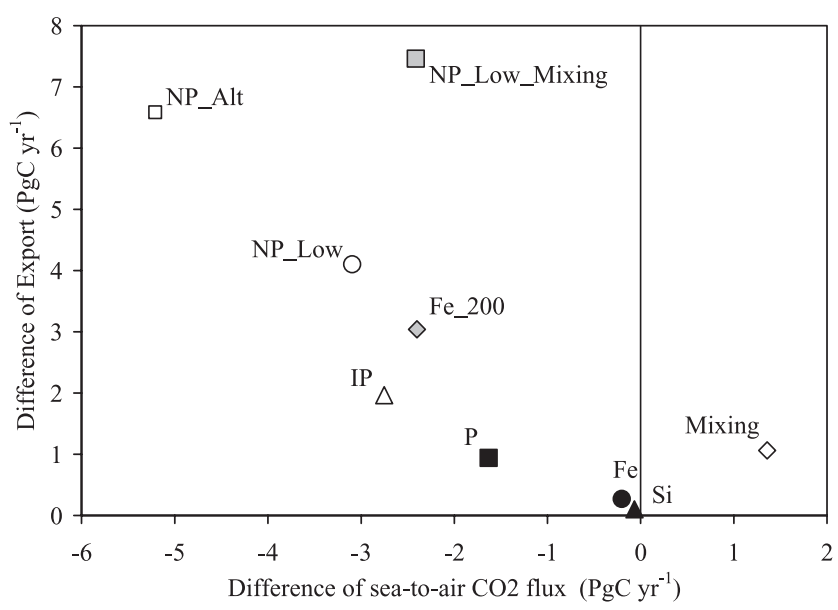

Figure 7. Export production difference $\left(\mathrm{PgC} \mathrm{a}^{-1}\right)$ versus sea-to-air $\mathrm{CO}_{2}$ flux difference $\left(\mathrm{PgC} \mathrm{a}{ }^{-1}\right)$ for the different sensitivity tests in comparison to the baseline simulation. Global mean, averaged over the last 5 years of experiment. 
oxygenation of the benthic boundary layer. This may result in the oxidation of the Fe which becomes not bio-available.

[52] The most realistic simulation (NP Low_Mix) was designed to be closest to the observed $\bar{b}$ enthos nutrient supply presented in Table 2 while still taking into account that some sedimentation of nutrients would occur in the coastal grid box because of the coarse model resolution. The Chla concentration in this simulation was improved compared to that of the baseline simulation, and showed an increase in Chla in the coastal ocean and in the equatorial upwelling areas and a decrease in the central oligotrophic gyres. Although the uncertainties in the nutrient fluxes are very large, this simulation suggests that global ocean biogeochemistry can be affected by the supply of nutrients from the coasts and that the global representation of biological activity may be improved by considering coastal processes. A better spatial coverage of the coastal nutrient fluxes would help to better constrain the exact impact of coastal processes on global ocean biogeochemistry. In particular, a higher grid resolution in this domain would change the realism of the oceanic circulation and nutrient exchange between coastal and open oceans.

[53] The simulation Fe_200 helps to distinguish between the role of $\mathrm{Si}$ and $\mathrm{P}$ on one hand and $\mathrm{Fe}$ on the other. The results of simulation $\mathrm{Fe} 200$ are similar to those of simulation NP_Low. Thus the improvements shown in the simulation NP_Low_Mix (and NP_Low) are mostly due to the increase of $\mathrm{Fe}$ over the other nutrients. Uncertainties in the data (Table 2) are particularly large regarding the supply and solubility of Fe. De Baar and de Jong [2001] mention that even for the best estimates the uncertainties may be as much as one order of magnitude. Thus within the uncertainty of the data, the supply of Fe from coastal processes appears to have the largest potential impact on open ocean biogeochemistry.

[54] Our study shows that changes in the supply of nutrients can have a direct impact on global $\mathrm{CO}_{2}$ fluxes. These results are sensitivity studies to the changes in nutrient supply only and do not consider corresponding changes in organic carbon. They illustrate the fact that the $\mathrm{CO}_{2}$ flux would be immediately modified if the source and balance of nutrients of the coastal ocean was to change.

[55] This study was possible because the PISCES biogeochemistry model is based on multi nutrient limitation of phytoplankton growth rates. The global simulations presented here correctly represent the main patterns of global ocean biogeochemistry. Nevertheless, our study has several limitations, including the limited representation of the iron cycle, the Redfield coupling of the nitrogen and phosphorus cycles, and the relatively simple representation of ecosystem dynamics and coarse resolution of the coastal region itself. Because our model takes into account the cycles of $\mathrm{Fe}, \mathrm{P}$, and $\mathrm{Si}$ separately the general conclusions regarding the importance of quantifying the ratio of nutrients supplied from the coast, and of resolving the uncertainties in the supply of Fe from the coast, still hold in spite of the recognized limitations of the model. An exact quantification of the respective impact of each nutrient however would likely depend on the parameterization of these nutrients in the model.
[56] Processes like vertical mixing or sediment resuspension over the continental shelves may modify the ratio of nutrients available for phytoplankton growth. The additional nutrient sources existing in the coastal ocean and their transport to the open ocean are therefore an important factor to consider in OBMs. Using a global biogeochemical model we assessed the impact of different nutrient ratio supplied to the coastal ocean on the surface Chla concentration, primary production and export of both coastal and open oceans. The sensitivity tests presented in this study highlight the importance of the nutrient ratio of the additional supply, over the quantity. The release of small amounts of nutrient from the coastal ocean may impact on open ocean structures (e.g., Chla concentration in equatorial upwelling areas, extent of subtropical oligotrophic gyres) if their ratio is different from the local nutrient limitation conditions. Under the pressure of climate change, accompanied by possible changes in general ocean circulation, and human activities, coastal nutrient supplies may evolve and the consequences may not be restricted to the primary production of the coastal ocean only.

[57] Acknowledgments. We thank O. Aumont for providing the PISCES biogeochemistry model and E. Buithenhuis for his support in model development. We also thank two anonymous reviewers for their comments. Computer time was provided by the German DKRZ. X. Giraud was funded through a Marie Curie Development Host Fellowship from the EU (HPMD-CT-2000-00038). RCOM-Nr. 0553.

\section{References}

Aumont, O., and L. Bopp (2006), Globalizing results from ocean in situ iron fertilization studies, Global Biogeochem. Cycles, 20, GB2017, doi:10.1029/2005GB002591.

Aumont, O., E. Maier-Reimer, S. Blain, and P. Monfray (2003), An ecosystem model of the global ocean including $\mathrm{Fe}, \mathrm{Si}, \mathrm{P}$ colimitations, Global Biogeochem. Cycles, 17(2), 1060, doi:10.1029/2001GB001745.

Blanke, B., and P. Delecluse (1993), Variability of the tropical Atlantic Ocean simulated by a general circulation model with two different mixed layer physics, J. Phys. Oceanogr., 23, 1363-1388.

Chester, R. (1990), Marine Geochemistry, 698 pp., Unwin-Hyman Ltd., London.

Cooper, L. W., T. E. Whitledge, J. M. Grebmeier, and T. Weingartner (1997), The nutrient, salinity, and stable oxygen isotope composition of Bering and Chukchi seas waters in and near the Bering Strait, J. Geophys. Res., 102(C6), 12,563-12,573.

Crossland, C. J. (2005), Coastal fluxes in the anthropocene, in The LandOcean Interactions in the Coastal Zone Project of the International Geosphere-Biosphere Programme Series: Global Change - The IGBP Series, edited by C. J. Crossland et al., vol. XX, 232 pp., Springer, New York.

da Cunha, L. C., E. T. Buitenhuis, C. Le Quéré, X. Giraud, and W. Ludwig (2007), Potential impact of changes in river nutrient supply on global ocean biogeochemistry, Global Biogeochem. Cycles, 21, GB4007, doi:10.1029/2006GB002718.

Dai, M.-H., and J.-M. Martin (1995), First data on trace metal level and behaviour in two major Arctic river-estuarine systems (Ob and Yenisey) and in the adjacent Kara Sea, Russia, Earth Planet. Sci. Lett., 131, 127141

de Baar, H. J. W., and J. T. M. de Jong (2001), Distributions, sources and sinks of iron in seawater. Review, chap. 5, in Biogeochemistry of Iron in Seawater, IUPAC Book Series on Analytical and Physical Chemistry of Environmental Systems, vol. 7, edited by D. Turner and K. A. Hunter, pp. $123-254$.

Döll, P., and B. Lehner (2002), Validation of a new global 30-min drainage direction map, J. Hydrol., 258, 214-231.

Eiras Garcia, C. A., V. M. Tavano Garcia, and C. R. McClain (2005), Evaluation of SeaWiFS chlorophyll algorithms in the Southwestern Atlantic and Southern Oceans, Remote Sens. Environ., 95, 125-137.

Fanning, K. A., L. C. Kendall, and P. R. Betzer (1982), Sediment resuspension by coastal waters: A potential mechanism for nutrient re-cycling on the ocean's margins, Deep Sea Res., Part I, 29(8A), 953-965. 
Gaspar, P., Y. Grégoris, and J. M. Lefevre (1990), A simple eddy-kineticenergy model for simulations of the ocean vertical mixing: Tests at Station Papa and long-term upper ocean study site, J. Geophys. Res., 95(C9), $16,179-16,193$

Gattuso, J. P., M. Frankignoulle, and R. Wollast (1998), Carbon and carbonate metabolism in coastal aquatic ecosystems, Ann. Rev. Ecol. Syst., $29,405-434$

Geider, R. J., H. L. MacIntyre, and T. M. Kana (1998), A dynamic regulatory model of phyto-planktonic acclimation to light, nutrients, and temperature, Limnol. Oceanogr., 43, 679-694.

Harrison, J. A., S. P. Seitzinger, A. F. Bouwman, N. F. Caraco, A. H. W Beusen, and C. J. Vörösmarty (2005), Dissolved inorganic phosphorus export to the coastal zone: Results from a spatially explicit, global model, Global Biogeochem. Cycles, 19, GB4S03, doi:10.1029/2004GB002357.

Hooker, S. B., and C. R. McClain (2000), The calibration and validation of SeaWiFS data, Prog. Oceanogr., 45, 427-465.

Jahnke, R. A., J. R. Nelson, R. L. Marinelli, and J. E. Eckman (2000), Benthic flux of biogenic elements on the Southeastern U.S. continental shelf: Influence of pore water advective transport and benthic microalgae, Cont. Shelf Res., 20, 109-127.

Jahnke, R. A., M. Richards, J. Nelson, C. Robertson, A. Rao, and D. Jahnke (2005), Organic matter remineralization and porewater exchange rates in permeable South Atlantic Bight continental shelf sediments, Cont. Shelf Res., 25, 1433-1452.

Johnson, K. S., F. P. Chavez, and G. E. Friederich (1999), Continental-shelf sediment as a primary source of iron for coastal phytoplankton, Nature, 398, 697-700.

Kalnay, E., et al. (1996), The NCEP/NCAR 40-year reanalysis project, Bull. Am. Meteorol. Soc., 77(3), 437-471.

Keeling, C. D., and T. P. Whorf (2005), Atmospheric CO2 records from sites $\mathrm{n}$ the SIO air sampling network, in Trends: A Compendium of Data on Global Change. Carbon Dioxide Information Analysis Center, Oak Ridge National Laboratory, U.S. Department of Energy, Oak Ridge, Tenn.

Le Quéré, C., J. C. Orr, P. Monfray, and O. Aumont (2000), Interannual variability of the oceanic sink of CO2 from 1979 through 1997, Global Biogeochem. Cycles, 14(4), 1247-1265.

Liu, K. K., K. Iseki, and S. Y. Chao (2000), Continental margin carbon fluxes, in The Changing Ocean Carbon Cycle, edited by R. B. Hanson, H. W. Ducklow, and J. G. Field, pp. 187-239, Cambridge Univ. Press, New York

Longhurst, A. (1998), Ecological Geography of the Sea, 398 pp., Academic Press, San Diego.

Ludwig, W., and J. L. Probst (1998), River sediment discharge to the oceans: Present-day controls and global budgets, Am. J. Sci., 298(4), $265-295$

Ludwig, W., J. L. Probst, and S. Kempe (1996), Predicting the oceanic input of organic carbon by continental erosion, Global Biogeochem. Cycles, 10(1), 23-41.

Madec, G., P. Delecluse, M. Imbard, and C. Lévy (1998), OPA 8.1 Ocean General Circulation Model Reference Manual, Note du Pôle de Modélisation, Institut Pierre-Simon Laplace (IPSL), France, N ${ }^{\circ} 11,91 \mathrm{pp}$

McManus, J., W. M. Berelson, K. H. Coale, K. S. Johnson, and T. E. Kilgore (1997), Phosphorus regeneration in continental margin sediments, Geochim. Cosmochim. Acta, 61(14), 2891-2907.

Muller-Karger, F. E., R. Varela, R. Thunell, R. Luerssen, C. Hu, and J. J. Walsh (2005), The importance of continental margins in the global carbon cycle, Geophys. Res. Lett., 32, L01602, doi:10.1029/2004GL021346.
Paerl, H. W. (1997), Coastal eutrophication and harmful algal blooms: Importance of atmospheric deposition and groundwaters as "new" nitrogen and other nutrient sources, Limnol. Oceanogr., 42, 1154-1165.

Pinkerton, M. H., S. J. Lavender, and J. Aiken (2003), Validation of SeaWiFS ocean color satellite data using a moored databuoy, J. Geophys. Res., 108(C5), 3133, doi:10.1029/2002JC001337.

Prandle, D. (1997), Tidal currents in the shelf seas - Their nature and impacts, Prog. Oceanogr., 40, 245-261.

Prandle, D., J. C. Hargreaves, J. P. McManus, A. R. Campbell, K. Duwe, A. Lane, P. Mahnke, S. Shimwell, and J. Wolf (2000), Tide, wave and suspended sediment modeling on an open coast - Holderness, Coastal Eng., 41, 237-267.

Rabouille, C., F. T. Mackenzie, and L. M. Ver (2001), Influence of the human perturbation on carbon, nitrogen, and oxygen biogeochemical cycles in the global coastal ocean, Geochim. Cosmochim. Acta, 65(21), $3615-3641$

Richardson, K. M., M. H. Pinkerton, P. W. Boyd, M. P. Gall, J. Zeldis, M. D. Oliver, and R. J. Murphy (2003), Validation of SeaWiFS data from around New Zealand, Adv. Space Res., 33(7), 1160-1167.

SCOR, W. G. (1975), Report of the second meeting on coastal upwelling processes, 10, Proc. Sci. Com. Oceanic Res., Fiel, F.R.G.

Slomp, C. P., and P. Van Cappellen (2004), Nutrient inputs to the coastal ocean through submarine groundwater discharge: Controls and potential impact, J. Hydrol., 295, 64-86.

Smith, S. V., et al. (2003), Humans, hydrology, and the distribution of inorganic nutrient loading to the ocean, Bioscience, 53(3), 235-245.

Spagnoli, F., and M. C. Bergamini (1997), Water-sediment exchange of nutrients during early diagenesis and resuspension of anoxic sediments from the northern Adriatic Sea shelf, Water Air Soil Pollut., 99, 541-556.

Tegen, I., and I. Fung (1995), Contribution to the atmospheric mineral aerosol load from land and surface modification, J. Geophys. Res., 100, $18,707-18,726$

Tengberg, A., E. Almroth, and P. Hall (2003), Resuspension and its effects on organic carbon recycling and nutrient exchange in coastal sediments: In situ measurements using new experimental technology, J. Exp. Mar Biol. Ecol., 285-286, 119-142.

Treguer, P., D. M. Nelson, A. J. van Bennekom, D. J. DeMaster, A. Leynaert, and B. Quequigner (1995), The silica balance in the world ocean: A reestimate, Science, 268(5209), 375-379.

Ver, L. M. B., F. T. Mackenzie, and A. Lerman (1999), Carbon cycle in the coastal zone: Effects of global perturbations and change in the past centuries, Chem. Geol., 159, 283-304.

Xing, J., F. Chen, and R. Proctor (1999), A two-dimensional slice model of the shelf edge region off the west coast of Scotland: Model response to realistic seasonal forcing and the role of the M2 tide, Cont. Shelf Res., 19, $1353-1386$

Zabel, M., A. Dahmke, and H. D. Schulz (1998), Regional distribution of diffusive phosphate and silicate fluxes through the sediment-water interface: The eastern South Atlantic, Deep Sea Res., Part I, 45(2-3), 277-300.

L. C. da Cunha, Leibnitz-Institut für Meereswissenschaften, Marine Biogeochemie, Düsternbrooker Weg 20, D-24105, Kiel, Germany.

X. Giraud, MARUM - Center for Marine Environmental Sciences and Faculty of Geosciences, University of Bremen, Fachbereich 5 Geowissenschaften, Postfach 330440, D-28334, Bremen, Germany. (xgiraud@ palmod.uni-bremen.de)

C. Le Quéré, School of Environmental Sciences, University of East Anglia, Norwich, UK 